\section{Novel technique for placement of overlapping self-expandable metal stents to close a massive pancreatitis-induced duodenal fistula}

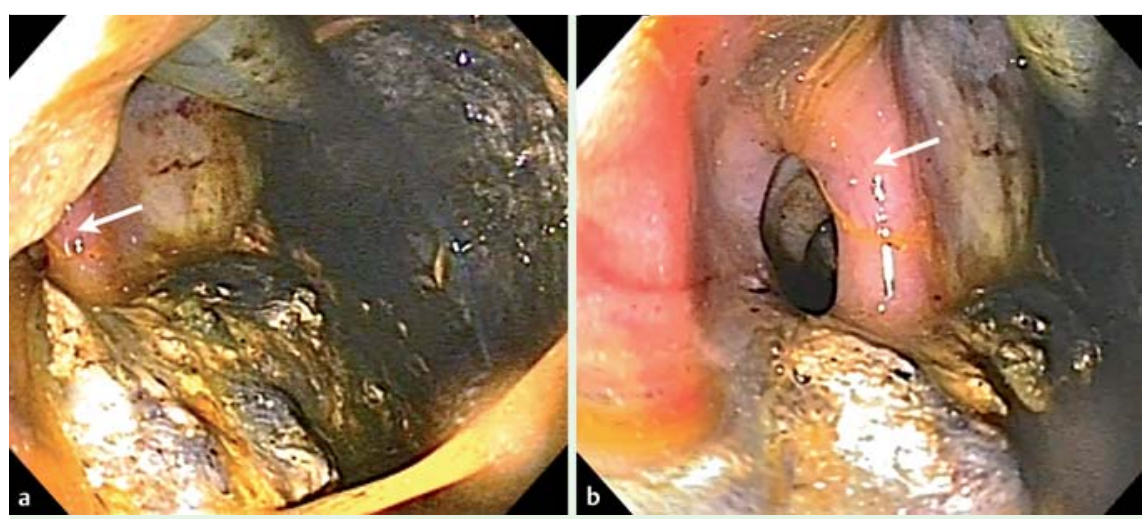

Fig. 1 Endoscopic images showing the massive fistula on the right. The arrow denotes the narrowed duodenal lumen. a The endoscope is situated just across the fistula passing into the remaining necrotic cavity with an indwelling catheter. b Endoscopic view from the duodenal bulb.

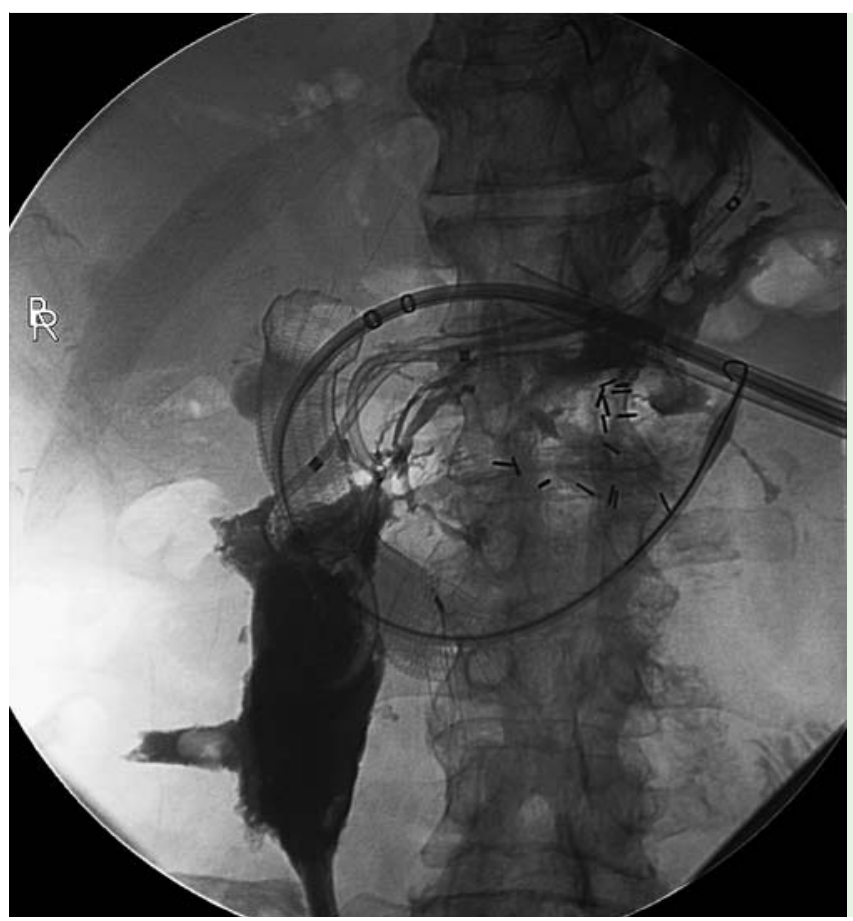

Fig. 2 Radiographic image immediately after deployment of initial partially covered esophageal stent through the transgastric sheath. Contrast injection shows continued leakage through the fistula communicating with a percutaneous pigtail catheter.
A 67-year-old man with infected pancreatic necrosis underwent serial endoscopic necrosectomies through a spontaneously formed massive duodenal fistula $(\bullet$ Fig. 1). He also required percutaneous drainage of a communicating paracolic gutter collection.

Despite resolution of necrosis, the fistula remained open with high-volume output through the percutaneous drain. The patient's severe coronary disease precluded surgical repair. Transoral placement of a fully covered esophageal self-expandable metal stent (SEMS) was attempted but failed due to looping of the delivery system within the stomach. To overcome this obstacle, a fluoroscopically guided percutaneous gastrostomy puncture was performed by an interventional radiologist; the tract was balloon dilated to $10 \mathrm{~mm}$, and a 26-Fr Amplatz Renal Introducer Sheath (Cook Urological Inc., Spencer, Indiana, USA) was inserted into the gastric lumen. Through the sheath, a guide wire was positioned into the distal duodenum, and a 12-cm long, 23-mm diameter, partially covered esophageal SEMS (Ultraflex; Boston Scientific, Natick, Massachusetts, USA) was deployed across the fistula under fluoroscopy.

Contrast injection showed continued leakage through the fistula ( Fig.2). Therefore, a 7-cm long, 18-mm diameter, fully covered esophageal SEMS (Alimaxx; Merit Medical Endotek, South Jordan, Utah, USA) was passed through the gastrostomy sheath and fluoroscopically deployed within the first stent in an overlapping fashion. Contrast injection confirmed luminal patency without further leakage ( $\bullet$ Fig. 3 ).

After 2 months, an upper gastrointestinal series revealed persistent absence of contrast extravasation. Fistula closure was endoscopically confirmed, and stent removal was performed by forceps extraction. The patient remains well 2 years later.

Gastroduodenal SEMS are typically utilized for palliation of malignant obstruction, but have also been used to close fistulas after gastric surgery [1-4] as well as to close iatrogenic duodenal perforations [5]. However, their use in the small intestine is limited by difficult placement due to imperfect delivery systems. Our case illustrates an innovative approach for SEMS deployment through a gastrostomy site to treat a massive pancreatitisinduced duodenal fistula.

Endoscopy_UCTN_Code_TTT_1AO_2AZ

Competing interests: None

\section{A. S. Rao', A. J. LeRoy ${ }^{2}$, E. A. Bonin', S. R. Sweetser ${ }^{1}$, T. H. Baron ${ }^{1}$}

${ }^{1}$ Division of Gastroenterology, Mayo Clinic, Rochester, Minnesota, USA

2 Department of Radiology, Mayo Clinic, Rochester, Minnesota, USA

\section{References}

1 Kriwanek S, Ott N, Ali-Abdullah S et al. Treatment of gastro-jejunal leakage and fistulization after gastric bypass with coated self-expanding stents. Obes Surg 2006; 16: 1669 1674

2 Salinas A, Baptista A, Santiago E et al. Selfexpandable metal stents to treat gastric leaks. Surg Obes Relat Dis 2006; 2: 570-572

3 Bona D, Sarli D, Saino G et al. Successful conservative management of benign gastrobronchial fistula after intrathoracic esophagogastrostomy. Ann Thorac Surg 2007; 84: $1036-1038$ 


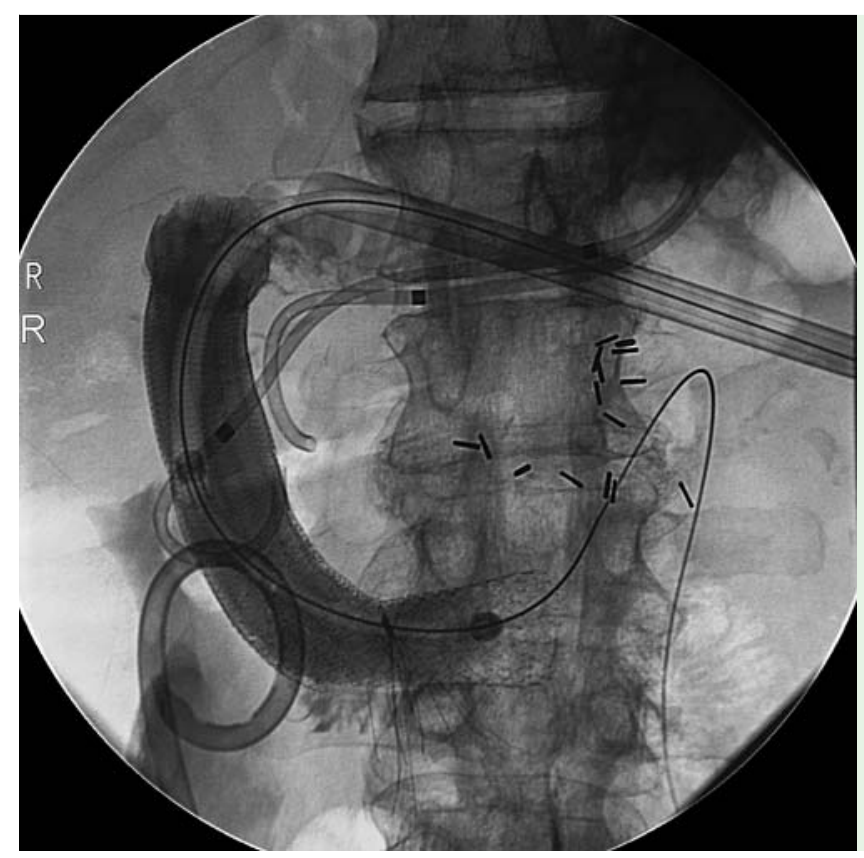

Fig. 3 Radiographic image immediately after deployment of second distally placed fully covered esophageal stent in overlapping fashion through the transgastric sheath. Contrast injection shows no residual extravasation through the fistulous tract.
4 Curcio G, Mocciaro F, Tarantino I et al. Selfexpandable metal stent for closure of a large leak after total gastrectomy. Case Rep Gastroenterol 2010; 4: 293-297

5 Small AJ, Petersen BT, Baron TH. Closure of a duodenal stent-induced perforation by endoscopic stent removal and covered selfexpandable metal stent placement (with video). Gastrointest Endosc 2007; 66: 1063-1065

\section{Bibliography}

Dol http://dx.doi.org/

10.1055/s-0031-1291760

Endoscopy 2012; 44: E163-E164

(c) Georg Thieme Verlag KG

Stuttgart · New York

ISSN 0013-726X

\section{Corresponding author}

\section{T. H. Baron, MD}

200 First Street SW

Rochester

MN 55905

USA

Fax: +1-507-266-3939

baron.todd@mayo.edu 